\title{
Effect of Fat-based versus Carbohydrate-based Enteral Feeding on Glycemic Control in Critically III Patients: A Randomized Clinical Trial
}

\author{
Mahdieh Nourmohammadi, Omid Moradi Moghadam', Mohammad Niakan Lahiji', Sevak Hatamian', Zahra Vahdat Shariatpanahi \\ National Nutrition and Food Technology Research Institute, Faculty of Nutrition and Food Technology, Shahid Beheshti University of Medical Sciences, \\ ${ }^{1}$ Department of Anesthesiology and Critical Care, Rasoul Akram Hospital, Iran University of Medical Sciences, Tehran, Iran
}

\section{Abstract}

Background and Aims: The aim of this study was to evaluate the preventive effects of high-fat enteral feeding on glycemic control and clinical outcomes in critically ill patients: a randomized clinical trial. Materials and Methods: This study was done on 42 normoglycemic patients admitted to Intensive Care Unit (ICU). Patients were randomly classified into three groups of 14 each. Control group (A) received carbohydrate-based diet (protein: 20\%, fat: 30\%, and carbohydrate: $50 \%$ ), study groups received two types of high-fat diet; Group B (protein: $20 \%$, fat: $45 \%$ including half of olive oil and half sunflower oil, and carbohydrate: $35 \%$ ); and Group C (protein: $20 \%$, fat: $45 \%$ including sunflower oil, and carbohydrate: $35 \%$ ) in the first $48 \mathrm{~h}$ of admission. Results: Basal characteristics of participants were the same. After the feeding trial, there was no difference between the groups in mean plasma and capillary glucose levels and insulin requirements. Serum high density lipoprotein (HDL)-cholesterol level was increased significantly in Group B on day 10 compared to admission level $(40.75 \pm 5.58 \mathrm{vs.} 43.56 \pm 2.25, P=0.05)$. We did not find any difference in organ failure involvement and mortality rate between groups. The number of ICU free days was significantly more in Group B compared to the control group $(P=0.04)$. Conclusion: High-fat diets have no preventive effect on stress hyperglycemia. High monounsaturated fat diet may increase serum HDL-cholesterol level and decrease the length of stay in ICU.

Keywords: Enteral nutrition, hyperglycemia, nutrition support, olive

\section{INTRODUCTION}

Glycemic abnormality, especially hyperglycemia, in patients without a history of diabetes, is a common response to any form of acute illness and is highly prevalent in patients who are admitted Intensive Care Unit (ICU)..$^{[1-5]}$ Rising of blood glucose levels has been associated with increased risk of organ failure, morbidity, and mortality in critically ill patients. ${ }^{[3,5,6]}$

It has been proposed that enteral formulas with lower carbohydrate and higher fat content with or without added fiber may prevent and control stress hyperglycemia in comparison with standard formulas. ${ }^{[7]}$ Many studies have been conducted in this area. Some trials were studied in long-term care facilities, rehabilitation, and other outpatient settings ${ }^{[8-10]}$ and some used oral nutrition support. ${ }^{[10,11]}$ The results of clinical trials which were conducted in critically ill patients requiring enteral or parenteral nutrition are controversial. ${ }^{[12-15]}$ Some studies have shown a beneficial effect of high-fat enteral

\begin{tabular}{|l|l|}
\hline \multicolumn{2}{|c|}{ Access this article online } \\
\hline Quick Response Code: & Website: \\
\hline & www.ijccm.org \\
\hline & \\
\hline
\end{tabular}

formula on glycemic control, ${ }^{[7,9,11,12,16]}$ whereas others showed no effect ${ }^{[15]}$ hence clinical practice guidelines have not made any nutritional recommendation for preventing or control of hyperglycemia yet and offered additional researches. ${ }^{[1]}$ On the other hand, based on studies, olive oil as a key component of Mediterranean diet has a beneficial effect on impaired glucose tolerance and lipid profile. ${ }^{[17,18]}$ These benefits have been attributed to the components of olive oil such as monounsaturated fatty acids (MUFAs) and polyphenols. ${ }^{[18]}$ Few studies have shown the preventive effect of high-fat diet especially contains olive oil without added fiber or antioxidants

Address for correspondence: Dr. Zahra Vahdat Shariatpanahi, 3, Baran, West Arghavan, Farahzadi Boulevard, Shahrak Qods, Zip Code: 1981619573, PO Box: 19395-4741, Tehran, I. R. Iran. E-mail: nutritiondata@yahoo.com

This is an open access article distributed under the terms of the Creative Commons Attribution-NonCommercial-ShareAlike 3.0 License, which allows others to remix, tweak, and build upon the work non-commercially, as long as the author is credited and the new creations are licensed under the identical terms.

For reprints contact: reprints@medknow.com

How to cite this article: Nourmohammadi M, Moghadam OM, Lahiji MN, Hatamian S, Shariatpanahi ZV. Effect of fat-based versus carbohydrate-based enteral feeding on glycemic control in critically ill patients: A randomized clinical trial. Indian J Crit Care Med 2017;21:500-5. 
on glycemic control and lipid profile. Therefore, we conducted this study to compare the effect of two types of fat-based enteral formula (olive oil fat-based formula and sunflower oil fat-based formula) with carbohydrate-based enteral formula, primarily on glycemic control and lipid profile and secondarily on the mortality, organ dysfunctions, and the length of stay in ICU in critically ill patients.

\section{Materials and Methods}

This randomized double-blind controlled trial received the Institutional Review Board approval for human research from the university hospital and was registered at irct.ir (IRCT2015100414901N7).

\section{Study population}

Forty-eight adult patients in both sexes, who were hospitalized in 32-bed ICU of a tertiary care university hospital and initiating enteral nutrition within $48 \mathrm{~h}$ following the hospital admission from August 2013 to December 2015, were included in this randomized double-blind study. Patients enrolled in other studies that were pregnant or with previous diabetes, hyperglycemia on admission, body mass index $\geq 30 \mathrm{~kg} / \mathrm{m}^{2}$, hyperlipidemia, liver failure, nephrotic syndrome, and any contraindication to enteral nutrition were excluded from the study. Patients who were discharged or died before the $5^{\text {th }}$ day of enteral nutrition administration were also excluded from the study. Participants were randomized by admitting to ICU and separated into three groups to receive high-protein enteral nutrition with different macronutrient compositions for at least 5 days; carbohydrate-based diet (Group A) (protein: 20\%, fat: 30\%, and carbohydrate: $50 \%$ ), olive oil fat-based diet (Group B) (protein: $20 \%$, fat: $45 \%$, and carbohydrate: $35 \%$ ), in which the olive oil included $50 \%$ of fat composition and sunflower fat-based diet (Group C) (protein: 20\%, fat: 45\%, and carbohydrate: 35\%). Randomization was performed according to a computer-generated random number table. The period of intervention was 14 days.

\section{Study procedures}

During the admission, written informed consent was obtained from the patients or their next of kin (when the patients cannot sign by themselves) after explaining the procedure of the study. Acute Physiology and Chronic Health Evaluation II (APACHE II), demographic information, and medical history were recorded at ICU admission. Planned enteral nutrition was administered after stabilizing the hemodynamic condition of each patient, which was dependent on the patient's clinical condition, and then the physician was allowed to feeding. Infusion of feeding was performed by gravity through intermittent technique, 6 times a day ( $6 \mathrm{am}, 9 \mathrm{am}, 12 \mathrm{pm}, 3 \mathrm{pm}, 6 \mathrm{pm}$, and $9 \mathrm{pm}$ ). The volume of administration was determined based on the calorie needs and tolerance of patients by starting from $50 \mathrm{~mL}$. Through the first $24 \mathrm{~h}$, if the patient could tolerate the feeding without any symptoms such as vomiting and suspected aspiration or gastric residual volume $>200 \mathrm{~mL}$, the infusion volume was increased to the goal volume. Gastrointestinal complications including high gastric residual volumes, diarrhea, vomiting, regurgitation, abdominal distension, constipation, and pulmonary aspiration were recorded every day. Gastric residuals were evaluated before each feeding for the first 2 days and then every $12 \mathrm{~h}$ for the remaining days.

Daily energy consumption was calculated by $25-30 \mathrm{kcal} / \mathrm{kg}$ for each patient based on weight and metabolic condition. Calorie needs were measured, and calorie intake was recorded daily for each individual during the study period. The volume ratio (VR) was calculated to measure the efficacy of daily nutritional administration: VR $(\%)=$ (volume administered/ volume prescribed) $\times 100$. Glucose was not used for infusion nor was propofol used for sedation.

\section{Laboratory data}

The glycemic profile of each patient was evaluated on a daily basis measuring venous fasting plasma glucose levels (at $6 \mathrm{AM}$ ) and the daily average capillary glucose level. Plasma glucose levels were measured by the glucose oxidase method. Patients received intravenous regular insulin, if the blood glucose level was higher than $200 \mathrm{mg} / \mathrm{dL}$. Fasting lipid profiles (triglycerides, total, high-density lipoprotein cholesterol [HDL-C], and low-density lipoprotein cholesterol [LDL-C]) were measured in days 0 and 10 of intervention at 6 am before feeding.

\section{Outcomes}

The primary outcome variables were the glycemic control and lipid profile in patients. The secondary outcome variables were the occurrence of organ failure and length of stay mortality in ICU. To evaluate the number of days that patients were in ICU, we calculated the number of ICU-free days, as early mortality could result in skewed data. Occurrence of organ failure was monitored during hospitalization. Mean sequential organ failure assessment (SOFA) score was used to determine the extent of a person's organ function. Each patient was evaluated daily for cardiovascular failure, central nervous system failure, coagulation failure, hepatic failure, and renal failure.

\section{Statistical analysis}

Differences between control and study groups were calculated from baseline to the end of intervention. Demographic data, baseline values, and outcome measures were compared with one-way ANOVA. Categorical data between the groups were compared using Chi square test. To compare the changes through the intervention, paired $t$-test and Wilcoxon test were used. Results were reported as mean \pm standard deviation or median $\left(\mathrm{Q}_{1}-\mathrm{Q}_{2}\right) . \mathrm{A} P \leq 0.05$ was considered statistically significant.

\section{RESULTS}

\section{Study population}

A total of 116 patients with study's inclusion criteria were accessible between August 2013 and December 2015. At last, 48 were enrolled in the study (16 were randomized to each group). Figure 1 shows the disposition of patients throughout the study.

Of 116 accessible patients that were allocated randomly by ICU admission to three intervention groups, 23 were excluded 
because of not starting the feeding through $48 \mathrm{~h}$ of admission. From patients who were fed enterally, 45 patients could not complete the intervention thereby were excluded (discharged or died before day 5 of intervention) from the study. Finally, 48 patients (16 in each group) were completed the intervention.

The baseline characteristics of the patients are shown in Table 1 . The study participants had a mean age of $58 \pm 23$ years and $70.8 \%(n=34)$ of them were male.

APACHE II scores and patients' reason for admission to ICU were not significantly different between three groups; therefore, the

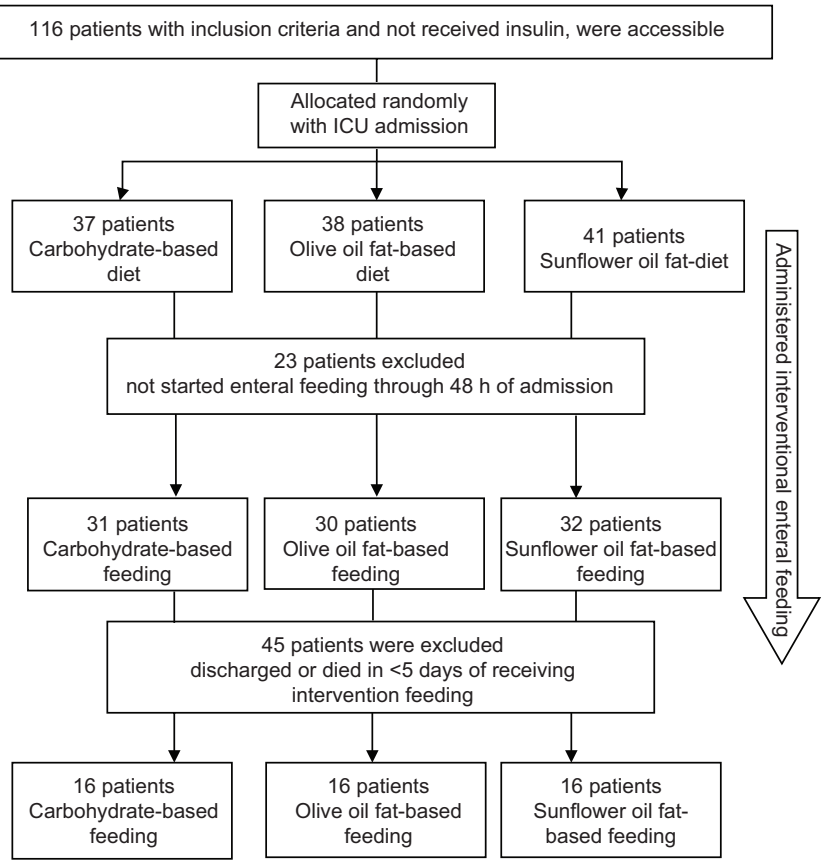

Figure 1: Disposition of patients throughout the study groups were homogeneous. There were no significant differences in age and gender between the three groups. Other characteristics including admission serum albumin, energy needs, blood glucose, and lipid profile were not significantly different between groups.

\section{Assessment of nutritional variables}

Participants of the study were on enteral nutrition for at least 5 days. The nutritional data of patients in three groups during the intervention are shown in Table 2 . There were no statically differences about the time of starting nutritional support, days of feeding, and mean energy intakes between the three groups. Gastric complications were also similar.

\section{Glycemic and lipid control}

Table 3 summarizes mean venous and capillary glucose levels in three groups. There was no difference in mean plasma glucose and capillary glucose level during the study period between three groups.

In Group A, 3 of 16, in Group B, 3 of 15, and in Group C, 4 of 15 patients required insulin $(P=0.60)$. Regular insulin requirements per day were 39.73 (21.3-50.5) unit in Group A, 36.2 (21.5-48.1) unit in Group B, and 38.3 (25.3-52.5) unit in Group $\mathrm{C}$ and were not significantly different $(P=0.73)$.

There was no difference in lipid profile of patients on admission between three groups. On day 10 of intervention, serum HDL-C was increased significantly in Group B with no change in other serum lipid variables [Table 4].

\section{Clinical outcomes}

Table 5 summarizes the clinical outcomes in study groups. There were no statistically significant differences in the SOFA score between the group of patients receiving the fat-based enteral feeding and those patients who were given the control. The overall in ICU mortality was $31.2 \%$ with six deaths in control

\begin{tabular}{|c|c|c|c|c|}
\hline Variable & $\begin{array}{l}\text { Carbohydrate-based diet } \\
\qquad(n=16)\end{array}$ & $\begin{array}{l}\text { Fat-based diet (olive oil) } \\
\qquad(n=16)\end{array}$ & $\begin{array}{c}\text { Fat-based diet } \\
\text { (sunflower oil) }(n=16)\end{array}$ & $P$ \\
\hline Age (year), mean $\pm \mathrm{SD}^{*}$ & $56.81 \pm 24.17$ & $58.50 \pm 22.25$ & $57.56 \pm 23.96$ & 0.99 \\
\hline Albumin $(\mathrm{g} / \mathrm{dL})$, mean $\pm \mathrm{SD}^{*}$ & $3.08 \pm 0.68$ & $3.19 \pm 0.51$ & $3.31 \pm 0.37$ & 0.49 \\
\hline Blood glucose $(\mathrm{mg} / \mathrm{dL})$, mean $\pm \mathrm{SD}^{*}$ & $113.96 \pm 28.28$ & $127.25 \pm 37.94$ & $129.06 \pm 31.35$ & 0.10 \\
\hline $\mathrm{LDL}-\mathrm{C}(\mathrm{mg} / \mathrm{dL}), \operatorname{mean} \pm \mathrm{SD}^{*}$ & $116 \pm 7.31$ & $126.50 \pm 12.74$ & $126.44 \pm 19.78$ & 0.06 \\
\hline $\mathrm{HDL}-\mathrm{C}(\mathrm{mg} / \mathrm{dL})$, mean $\pm \mathrm{SD}^{*}$ & $38.69 \pm 4.76$ & $41.75 \pm 5.85$ & $40.81 \pm 6.51$ & 0.12 \\
\hline Total cholesterol (mg/dL), mean $\pm \mathrm{SD}^{*}$ & $150.81 \pm 15.61$ & $168 \pm 18.95$ & $168.81 \pm 33.35$ & 0.06 \\
\hline Triglyceride (mg/dL), mean $\pm \mathrm{SD}^{*}$ & $135.52 \pm 33.07$ & $145.75 \pm 28.17$ & $144.13 \pm 43.69$ & 0.73 \\
\hline APACHE II, mean \pm SD* & $17 \pm 5.72$ & $17.25 \pm 4.64$ & $16.38 \pm 4.55$ & 0.88 \\
\hline Mean energy needs (kcal/day) $\left(\mathrm{Q}_{1}-\mathrm{Q}_{3}\right)^{* *}$ & $1986.90(1862.78-2109.11)$ & $1907.40(1611.34-2073.56)$ & $2009.73(1658.12-2038.62)$ & 0.93 \\
\hline \multicolumn{5}{|l|}{ Sex, $n(\%)^{* * *}$} \\
\hline Male & $14(87.5)$ & $10(62.5)$ & $10(62.5)$ & 0.19 \\
\hline Female & $2(12.5)$ & $6(37.5)$ & $6(37.5)$ & \\
\hline \multicolumn{5}{|l|}{ Disease, $n(\%)^{* * *}$} \\
\hline Medical & $10(62.5)$ & $12(75)$ & $9(56.3)$ & 0.85 \\
\hline Surgery & $4(25)$ & $3(18.8)$ & $5(31.3)$ & \\
\hline Trauma & $2(12.5)$ & $1(6.2)$ & $2(12.5)$ & \\
\hline
\end{tabular}




\begin{tabular}{|c|c|c|c|c|}
\hline Variable & $\begin{array}{l}\text { Carbohydrate-based diet } \\
\qquad(n=16)\end{array}$ & $\begin{array}{l}\text { Fat-based diet (olive oil) } \\
\qquad(n=16)\end{array}$ & $\begin{array}{l}\text { Fat-based diet (sunflower oil) } \\
\qquad(n=16)\end{array}$ & $P$ \\
\hline Enteral feeding days $\left(\mathrm{Q}_{1}-\mathrm{Q}_{3}\right)^{*}$ & $13(10-14)$ & $14(8.5-14)$ & $14(6.25-14)$ & 0.67 \\
\hline Mean energy intake ( $\mathrm{kcal} /$ day), mean $\pm \mathrm{SD}^{* *}$ & $1454.65 \pm 366.39$ & $1409.90 \pm 389.35$ & $1434.85 \pm 522.17$ & 0.95 \\
\hline Volume ratio (\%), mean $\pm \mathrm{SD}^{* *}$ & $91.31 \pm 23.34$ & $90.07 \pm 22.14$ & $89.77 \pm 33.14$ & 0.96 \\
\hline Gastric residual volume $>250 \mathrm{~mL}, n(\%)^{* * *}$ & $6(37.5)$ & $4(26)$ & $5(31.3)$ & 0.74 \\
\hline Diarrhea, $n(\%) * * *$ & $3(19.7)$ & $2(13.5)$ & $3(19.7)$ & 0.85 \\
\hline
\end{tabular}

*Mann-Whitney, **One-way ANOVA, ***Chi-square. SD: Standard deviation

\begin{tabular}{lccc}
\hline Table 3: Blood glucose status in study groups through intervention & & \\
\hline Variable & $\begin{array}{c}\text { Carbohydrate-based diet } \\
(\boldsymbol{n}=\mathbf{1 6})\end{array}$ & $\begin{array}{c}\text { Fat-based diet (olive oil) } \\
(\boldsymbol{n}=\mathbf{1 6})\end{array}$ & $\begin{array}{c}\text { Fat-based diet (sunflower oil) } \\
(\boldsymbol{n}=\mathbf{1 6})\end{array}$ \\
\hline Mean 6 AM blood glucose (mg/dL), mean $\pm \mathrm{SD}$ & $123.53 \pm 26.6$ & $129.23 \pm 31$ & $125.66 \pm 30.4$ \\
Mean capillary glucose (mg/dL), mean $\pm \mathrm{SD}$ & $154.53 \pm 29.6$ & $149.23 \pm 31$ & $152.66 \pm 30.4$ \\
\hline
\end{tabular}

*One-way ANOVA. SD: Standard deviation

\begin{tabular}{|c|c|c|c|}
\hline Variable & $\begin{array}{c}\text { Before } \\
\text { intervention }\end{array}$ & Day 10 & $P a$ \\
\hline \multicolumn{4}{|l|}{ LDL-C (mg/dL) } \\
\hline Carbohydrate-based diet & $116 \pm 7.31$ & $113.5(105.25-134.5)$ & 0.83 \\
\hline Fat-based diet (olive oil) & $126.5 \pm 12.74$ & $114.5(114-127.25)$ & 0.31 \\
\hline Fat-based diet (sunflower oil) & $126.44 \pm 19.78$ & $131(113.5-145)$ & 0.75 \\
\hline$P^{\mathrm{b}}$ & 0.06 & 0.24 & \\
\hline \multicolumn{4}{|l|}{ HDL-C (mg/dL) } \\
\hline Carbohydrate-based diet & $38.69 \pm 4.76$ & $38.69 \pm 5.10$ & 1 \\
\hline Fat-based diet (olive oil) & $40.75 \pm 5.85$ & $43.56 \pm 2.25$ & 0.05 \\
\hline Fat-based diet (sunflower oil) & $40.81 \pm 6.51$ & $41.18 \pm 4.72$ & 0.81 \\
\hline$P^{\mathrm{b}}$ & 0.12 & 0.53 & \\
\hline \multicolumn{4}{|l|}{ Total cholesterol (mg/dL) } \\
\hline Carbohydrate-based diet & $150.81 \pm 15.61$ & $162.56 \pm 16.51$ & 0.41 \\
\hline Fat-based diet (olive oil) & $168 \pm 18.95$ & $165.75 \pm 7.66$ & 0.64 \\
\hline Fat-based diet (sunflower oil) & $168.81 \pm 33.35$ & $175.25 \pm 32.15$ & 0.31 \\
\hline$P^{\mathrm{b}}$ & 0.06 & 0.09 & \\
\hline \multicolumn{4}{|l|}{ Triglyceride (mg/dL) } \\
\hline Carbohydrate-based diet & $135.52 \pm 33.07$ & $144.06 \pm 23.19$ & 0.43 \\
\hline Fat-based diet (olive oil) & $145.75 \pm 28.17$ & $135.06 \pm 24.48$ & 0.26 \\
\hline Fat-based diet (sunflower oil) & $144.13 \pm 43.69$ & $151.56 \pm 39.08$ & 0.40 \\
\hline$P^{\mathrm{b}}$ & 0.73 & 0.74 & \\
\hline
\end{tabular}

${ }^{\text {aPaired }} t$-test, ${ }^{\mathrm{b} O n e-w a y ~ A N O V A . ~ L D L-C: ~ L o w-d e n s i t y ~ l i p o p r o t e i n ~}$

cholesterol; HDL-C: High-density lipoprotein cholesterol

group, three deaths in Group B, and six deaths in Group C, with no significant difference. Length of ICU-free days was calculated by subtracting the number of ICU days from 14 days or survival time. The number of ICU-free days was significantly more in Group B compared to the control group $(0.56 \pm 1.21$ Group A, $1.50 \pm 2.80$ Group $\mathrm{B}$, and $1.18 \pm 2.50$ Group $\mathrm{C}, P=0.04$ ).

\section{Discussion}

\section{Glycemic control}

The results of this study showed that the use of high-fat low-carbohydrate enteral formula in normoglycemic patients was well tolerated and did not have any effect on carbohydrate metabolism to prevent hyperglycemia compared with a control high-protein diet. Our findings are similar to Wewalka's pilot study which was conducted on sixty medical critically ill hyperglycemic patients with either fat-based or glucose-based enteral nutrition. They found no difference in glucose levels between two groups. ${ }^{[15]}$ In another study which was conducted on 147 traumatic critically ill patients, low-carbohydrate and high-fat (MUFA) enteral formula was more effective for glycemic control in critically ill patients compared with a standard enteral formula. No differences were observed between the two groups with regard to mortality, ICU stay, and gastrointestinal complications. ${ }^{[16]}$ Mesejo et al. enrolled fifty critically ill patients with diabetes mellitus or stress hyperglycemia to receive a high protein, high-fat formula (starch, fructose, MUFA, and soluble fiber), or a high protein formula for 14 days. Patients who received high-fat formula had a significant reduction in plasma glucose levels, capillary glucose levels, and insulin requirements in comparison to patients on a conventional high-protein diet. This better glycemic control does not modify ICU length of stay, infectious complications, mechanical ventilation, and mortality. ${ }^{[12]}$ In Mesejo's study, fiber intake and type of carbohydrate were different between two groups and this difference might affect the results. In Huschak et al. study, 33 severe multiple trauma patients (injury severity score $31.6 \pm 11.5)$ received either a glucose-based diet or a fat-based diet (olive oil). They concluded that patients, who received fat-based diet, had a better glucose control and shorter hospitalization. ${ }^{[14]}$ In Huschak's study, diets were administrated by total parenteral nutrition for 6 days and then transmitted to enteral nutrition. In another study, the effects of long-term feeding with a low carbohydrate content and high fat (MUFAs, fish oil, chromium, and antioxidants) were compared with a standard formula, on glycemic control in 105 tube-fed type II diabetic patients. Better glucose control was seen in patients fed with high-fat diet. ${ }^{[19]}$ This study was not conducted in 


\begin{tabular}{lccc}
\hline Table 5: Clinical outcomes in study groups & & \\
\hline Variable & $\begin{array}{c}\text { Carbohydrate-based diet } \\
(\boldsymbol{n}=\mathbf{1 6})\end{array}$ & $\begin{array}{c}\text { Fat-based diet (olive oil) } \\
(\boldsymbol{n}=\mathbf{1 6 )}\end{array}$ & $\begin{array}{c}\text { Fat-based diet (sunflower oil) } \\
(\boldsymbol{n}=16)\end{array}$ \\
\hline ICU-free days* (mean $\pm \mathrm{SD})$ & $0.56 \pm 1.21^{\mathrm{a}}$ & $1.50 \pm 2.80^{\mathrm{b}}$ & $1.18 \pm 2.50^{\mathrm{a}, \mathrm{b}}$ \\
Mean SOFA score* (mean $\pm \mathrm{SD})$ & $7.15 \pm 1.35$ & $7.27 \pm 1.81$ & $6.71 \pm 1.76$ \\
Death, $n$ (\%)** & $6(37.5)$ & $3(18.7)$ & 0.04 \\
\hline
\end{tabular}

Values with different superscript letters are significantly different. *One-way ANOVA, **Chi-square. ICU: Intensive Care Unit; SOFA: Sequential organ failure assessment; SD: Standard deviation

critically ill patients with stress hyperglycemia. Furthermore, administration of fish oil, chromium, and antioxidants might affect the results.

The studies which have reported better glycemic control with high-fat diet in ICU were conducted on hyperglycemic patients or on patients with severe stress. In contrast to mentioned studies, our study was conducted on normoglycemic patients admitted to ICU to assay the preventive effect of high-fat diet on stress hyperglycemia.

\section{Lipid profile}

As in mentioned studies, both high-fat diets did not have any adverse effects on lipid variables. In addition, gastrointestinal complications in both high-fat diets were similar to carbohydrate-based diet. Studies have shown that high-monounsaturated fat diets decrease serum triglyceride and very LDL-C (VLDC-C) and increase serum HDL-C in comparison to high carbohydrate diets. ${ }^{[20,21]}$ In our study, the administration of a high monounsaturated-fat diet showed a significant increase in HDL-C compared to other groups, but the decrease in serum triglyceride and VLDL-C was not significant. This may be due to the time of serum lipid levels measuring which was done on day 10 of intervention whereas longer time was needed to see changes on serum lipid variables.

\section{Clinical outcomes}

In our study, high-fat low-carbohydrate diets did not reduce organ failure involvement and mortality rate but the length of stay in ICU was reduced in high-olive fat group. Shorter duration of hospitalization was seen in critically ill patients with stress hyperglycemia with a low carbohydrate content formula and high MUFAs. ${ }^{[14]}$ Olive oil contains antioxidant and anti-inflammatory components which can reduce inflammation in critically ill patient and shorten the duration of hospitalization. ${ }^{[22]}$

\section{ConcLusion}

Our study showed that high-fat diets did not have any preventive effect on glycemic control of critically ill patients. Furthermore, blood lipids were not changed with high-fat diets except for the rise in HDL-C in the high olive oil fat diet. We did not find any difference in organ failure involvement and mortality rate between the groups, but the duration of hospitalization in ICU was significantly lower in high olive oil fat diet. We might conclude better clinical outcomes in high olive oil fat diet if larger patient samples were studied.
In addition, the change on other lipid parameters might be seen in high olive oil fat diet if enough time had elapsed for measuring these variables.

\section{Acknowledgment}

We convey our gratitude to the National Nutrition and Food Technology Research Institute, Tehran, Iran, and the ICU staff at Rasoul Akram Hospital.

\section{Financial support and sponsorship}

Funding of this study was provided by the National Nutrition and Food Technology Research Institute.

\section{Conflicts of interest}

There are no conflicts of interest.

\section{ReFERENCES}

1. McClave SA, Taylor BE, Martindale RG, Warren MM, Johnson DR, Braunschweig C, et al. Guidelines for the provision and assessment of nutrition support therapy in the adult critically ill patient: Society of Critical Care Medicine (SCCM) and American Society for Parenteral and Enteral Nutrition (A.S.P.E.N.). JPEN J Parenter Enteral Nutr 2016;40:159-211.

2. Guo YJ, Zhou Y, Zhang SY, Wei Q, Huang Y, Xia WQ, et al. Optimal target range for blood glucose in hyperglycaemic patients in a neurocritical care unit. Diab Vasc Dis Res 2014;11:352-8.

3. Chase JG, Pretty CG, Pfeifer L, Shaw GM, Preiser JC, Le Compte AJ, et al. Organ failure and tight glycemic control in the SPRINT study. Crit Care 2010;14:R154.

4. Parsons $\mathrm{P}$, Watkinson P. Blood glucose control in critical care patients -A review of the literature. Nurs Crit Care 2007;12:202-10.

5. Wagstaff AE, Cheung NW. Diabetes and hyperglycemia in the critical care setting: Has the evidence for glycemic control vanished? (Or ... is going away?). Curr Diab Rep 2014;14:444.

6. Clain J, Ramar K, Surani SR. Glucose control in critical care. World J Diabetes 2015;6:1082-91.

7. Hise ME, Fuhrman MP. The effect of diabetes-specific enteral formulae on clinical and glycemic indicators. Pract Gastroenterol 2009;20:22-30.

8. Elia M, Ceriello A, Laube H, Sinclair AJ, Engfer M, Stratton RJ, et al. Enteral nutritional support and use of diabetes-specific formulas for patients with diabetes: A systematic review and meta-analysis. Diabetes Care 2005;28:2267-79.

9. Craig LD, Nicholson S, SilVerstone FA, Kennedy RD. Use of a reduced-carbohydrate, modified-fat enteral formula for improving metabolic control and clinical outcomes in long-term care residents with type 2 diabetes: Results of a pilot trial. Nutrition 1998;14:529-34.

10. León-Sanz M, García-Luna PP, Sanz-París A, Gómez-Candela C, Casimiro C, Chamorro J, et al. Glycemic and lipid control in hospitalized type 2 diabetic patients: evaluation of 2 enteral nutrition formulas (low carbohydrate-high monounsaturated fat vs high carbohydrate). JPEN J Parenter Enteral Nutr 2005;29:21-9.

11. Yokoyama J, Someya Y, Yoshihara R, Ishii H. Effects of high-monounsaturated fatty acid enteral formula versus high-carbohydrate enteral formula on plasma glucose concentration and 
insulin secretion in healthy individuals and diabetic patients. J Int Med Res 2008;36:137-46.

12. Mesejo A, Acosta JA, Ortega C, Vila J, Fernández M, Ferreres J, et al. Comparison of a high-protein disease-specific enteral formula with a high-protein enteral formula in hyperglycemic critically ill patients. Clin Nutr 2003;22:295-305.

13. de Azevedo JR, de Araujo LO, da Silva WS, de Azevedo RP. A carbohydrate-restrictive strategy is safer and as efficient as intensive insulin therapy in critically ill patients. J Crit Care 2010;25:84-9.

14. Huschak G, Zur Nieden K, Hoell T, Riemann D, Mast H, Stuttmann R, et al. Olive oil based nutrition in multiple trauma patients: A pilot study. Intensive Care Med 2005;31:1202-8.

15. Wewalka M, Drolz A, Zauner C. Influence of fat-based versus glucose-based enteral nutrition formulas on glucose homeostasis. Crit Care 2013;17 Suppl 2:P250.

16. Mohri T, Matsuda H, Kubo N, Inadome N, Nakamori Y, Fujimi S, et al. The effect on glycemic control of a low-carbohydrate, high-fat enteral formula in critically ill patients admitted to a trauma and critical care center. Nihon Kyukyu Igakukai Zasshi 2011;22:871-7.

17. Saleh NK, Saleh HA. Olive oil improved the impairment of in vitro insulin-stimulated glucose uptake by diaphragm in ovariectomized female wistar rats. Exp Gerontol 2010;45:964-9.

18. Violi F, Loffredo L, Pignatelli P, Angelico F, Bartimoccia S, Nocella C, et al. Extra virgin olive oil use is associated with improved post-prandial blood glucose and LDL cholesterol in healthy subjects. Nutr Diabetes 2015;5:e172.

19. Pohl M, Mayr P, Mertl-Roetzer M, Lauster F, Haslbeck M, Hipper B, et al. Glycemic control in patients with type 2 diabetes mellitus with a disease-specific enteral formula: Stage II of a randomized, controlled multicenter trial. JPEN J Parenter Enteral Nutr 2009;33:37-49.

20. Garg A. High-monounsaturated-fat diets for patients with diabetes mellitus: A meta-analysis. Am J Clin Nutr 1998;67 3 Suppl: 577S-82S.

21. Shahbazi S, Vahdat Shariatpanahi Z. Prevention of type 2 diabetes mellitus by changes in diet among subjects with abnormal glucose metabolism: a randomized clinical trial. Int $\mathrm{J}$ Diabetes Dev Ctries 2017. [doi: 10.1007/s13410-017-0548-3]. First Online: 2017 January 14.

22. Najmi M, Vahdat Shariatpanahi Z, Tolouei M, Amiri Z. Effect of oral olive oil on healing of $10-20 \%$ total body surface area burn wounds in hospitalized patients. Burns 2015;41:493-6. 